\title{
Use of personal mobile devices to record patient data by Canadian emergency physicians and residents
}

\author{
Kerry E. Walker, BSc, BEd, MD*; David Migneault, MDCM, MSBe ${ }^{\dagger \ddagger \S}$; Heather C. Lindsay, MD, MPH ${ }^{\dagger \S ;}$ \\ Riyad B. Abu-Laban, MD, MHSc ${ }^{\dagger \S \uparrow}$
}

\begin{abstract}
CLINICIAN'S CAPSULE
What is known about the topic?

Personal mobile device use to record patient data is prevalent throughout hospitals and may conflict with patient privacy.

What did this study ask?

To what extent and purpose do Canadian physicians and residents use personal mobile devices to record patient data in the emergency department?

What did this study find?

Clinicians who use personal mobile devices to record patient data believing it is beneficial to patient care may be unaware of relevant regulations.

Why does this study matter to clinicians?

Personal mobile device recording of patient data is common, so further research is needed to determine patient benefit while maintaining patient confidentiality.
\end{abstract}

\section{ABSTRACT}

Objective: Use of personal mobile devices to record patient data appears to be increasing, but remains poorly studied. We sought to determine the extent and reasons that Canadian emergency physicians (EPs) and emergency medicine residents use personal mobile devices to record patient data in the emergency department (ED).

Methods: A national survey was distributed to Canadian EPs and residents between 27/02/17 and 23/03/17. This captured demographics, frequency, and purpose of personal mobile device use to record patient data in the ED. It also asked about obtaining consent, security of information, implications for patient care, and knowledge of relevant regulations.

Results: The response rate was $23.1 \%$ (406 participants). A third $(31.5 \%)$ reported using personal mobile devices to record patient data. Most (78.1\%) did so more than once a month, and
$7.0 \%$ did so every shift. Reasons cited included beliefs that using personal mobile devices to record patient data improves care by consultants $(36.7 \%)$, expedites care $(31.3 \%)$, and advances medical education (32.8\%). Consent was rarely or never documented and a minority of participants $(10.9 \%)$ indicated they did not obtain consent. More than half of participants $(53.2 \%)$ reported being unaware of applicable regulations.

Conclusions: This is the first Canadian study on the use of personal mobile devices to record patient data in the ED. Our findings demonstrate current practice may risk privacy breaches. Personal mobile device use to record patient data in the ED is common and Canadian EPs and residents believe that this practice enhances patient care.

\section{RÉSUMÉ}

Objectif: L'utilisation des appareils mobiles personnels (AMP) pour l'enregistrement de données sur les malades semble de plus en plus fréquente, mais elle a été peu examinée jusqu'à maintenant. Aussi l'étude visait-elle à déterminer l'étendue de la pratique et les raisons pour lesquelles les médecins d'urgence (MU) et les résidents dans le domaine, au Canada, utilisent les AMP pour enregistrer des données sur les malades au service des urgences (SU).

Méthode: Un questionnaire d'enquête nationale a été envoyé au MU et aux résidents en la matière, au Canada, entre le 2 février 2017 et le 23 mars 2017. On a ainsi recueilli des données démographiques, de même que des renseignements sur la fréquence de la pratique et les raisons motivant l'utilisation des AMP pour la collecte de données sur les malades au SU. Des questions portaient aussi sur l'obtention du consentement, la sécurité de l'information, la portée de l'acte sur les soins aux malades et la connaissance de la réglementation applicable.

Résultats: Le taux de réponse a atteint 23,1\% (406 participants). Un tiers $(31,5 \%)$ des répondants ont indiqué faire

From *University of British Columbia Emergency Medicine Residency Program, Vancouver Site, Vancouver, BC; †Emergency Department, Vancouver General Hospital, Vancouver Coastal Health, Vancouver, BC; $\neq$ Emergency Department, British Columbia Children's Hospital, Provincial Health Services Authority, Vancouver, BC; §Department of Emergency Medicine, Faculty of Medicine, University of British Columbia, Vancouver, BC; and the ๆCentre for Clinical Epidemiology and Evaluation, Vancouver Coastal Health Research Institute, Vancouver, BC.

Correspondence to: Dr. Kerry Walker, University of British Columbia Emergency Medicine Residency Program, Vancouver Site, Diamond Health Care Centre, 2775 Laurel St. 11 ${ }^{\text {th }}$ Floor, Vancouver, BC, V5Z 1M9; Email: kerewalk@alumni.ubc.ca

(c) Canadian Association of Emergency Physicians

CJEM 2019;21(4):455-459

DOI 10.1017/cem.2019.29 
usage d'AMP pour enregistrer des données sur les malades. La plupart $(78,1 \%)$ les utilisaient plus d'une fois par mois et $7,0 \%$, à toutes les périodes de travail. Les raisons invoquées le plus souvent comprenaient l'opinion selon laquelle I'utilisation des AMP pour l'enregistrement de données sur les malades améliorait les soins par les consultants $(36,7 \%)$, accélérait la prestation de soins $(31,3 \%)$ et faisait progresser la formation médicale $(32,8 \%)$. Le consentement était rarement documenté, voire jamais, et une minorité de répondants $(10,9 \%)$ ont indiqué ne pas avoir obtenu le consentement des patients. Plus de la moitié des participants $(53,2 \%)$ ont déclaré ne pas être courant de l'existence de règlements applicables.
Conclusion: II s'agit là de la première étude sur l'utilisation des AMP au Canada pour l'enregistrement de données sur les malades au SU. D'après les résultats de I'enquête, la pratique pourrait comporter des risques d'atteinte à la vie privée. L'usage des AMP pour l'enregistrement de données sur les malades au SU est courant, et les MU comme les résidents sont d'avis que la pratique améliore les soins aux malades.

Keywords: Confidentiality, emergency department, emergency medicine, mobile device, personal health information, privacy

\section{BACKGROUND}

Personal mobile devices are prevalent throughout hospitals. ${ }^{1}$ Use of personal mobile devices within the clinical setting can improve patient care ${ }^{2}$ including documentation of treatment ${ }^{3}$ and imaging transfer. ${ }^{4}$

Although patients are receptive to personal mobile device use, ${ }^{5}$ concerns around privacy and confidentiality have been raised. ${ }^{6}$ Previous research has shown a lack of awareness of, or adherence to, relevant guidelines, often resulting in breaches of patient confidentiality. ${ }^{7}$ However, research on personal mobile device use in the emergency department (ED) is limited. ${ }^{7}$ A UK study on photo-documentation found $45.2 \%$ of EDs did not have relevant policies in place, and only $7.5 \%$ documented consent for use. ${ }^{8}$

The purpose of this study was to determine the frequency of personal mobile device use to record patient data by emergency physicians (EPs) and emergency medicine residents and to investigate current practices.

\section{METHODS}

\section{Online survey instrument and design}

The University of British Columbia (UBC) Survey Tool, which is Freedom of Information and Privacy Protection Act (FIPPA) compliant, was used to capture anonymous, confidential data from respondents.

Thirteen questions were captured: demographics, personal mobile device use to record patient data and rationale, consent, documentation format, confidentiality, and limitations (Supplementary Material). Online questions were coded into numerical data or left in an open-text format as applicable. Non-responses were excluded from analysis.

\section{Ethics and approval}

The UBC Research Ethics Review Board approved the study, and consent was assumed based on participation after reading the supplied information.

\section{Distribution and sampling}

The format followed standard physician survey guidelines. ${ }^{9}$ From February 27, 2017, to March 23, 2017, the Canadian Association of Emergency Physicians (CAEP) sent three email blasts to consenting CAEP members. Documents were provided in French and English.

\section{Data analysis}

Descriptive statistics are reported as frequencies and percentages. Open-text responses were thematically analyzed by reviewers and reported qualitatively.

\section{RESULTS}

One thousand eight-hundred CAEP members who agreed to participate in research surveys were contacted. Of these, 415 responded (23.1\%). Nine responses were excluded owing to insufficient data, resulting in 406 participants. The majority of EP and resident respondents had formal training in emergency medicine (EM; $80.3 \%$ and $78.2 \%$, respectively) and worked in large 


\begin{tabular}{|c|c|c|}
\hline & & $N(\%)^{*}$ \\
\hline \multirow{6}{*}{$\begin{array}{l}\text { Why do respondents record patients' data on their } \\
\text { personal mobile devices in the ED? }\end{array}$} & Communication with consultants & $100(78.1)$ \\
\hline & Medical education & $84(65.6)$ \\
\hline & Personal library & $45(35.2)$ \\
\hline & With patients at the bedside & $39(30.5)$ \\
\hline & To include it in the patients' medical record & $16(12.5)$ \\
\hline & Other $^{\dagger}$ & $13(10.2)$ \\
\hline \multirow{11}{*}{ Which patients' data is documented? } & Imaging (x-rays, US, CT, MRI) & $103(80.5)$ \\
\hline & ECGs & $100(78.1)$ \\
\hline & Wounds/lacerations & 78 (60.9) \\
\hline & Physical examination findings & $31(24.2)$ \\
\hline & Patient demographics & 28 (21.9) \\
\hline & Laboratory results & $16(12.5)$ \\
\hline & Vital signs/monitors & $12(9.4)$ \\
\hline & Video recording of interaction/clinical encounter & $2(1.6)$ \\
\hline & Audio recording of interaction/clinical encounter & $1(0.8)$ \\
\hline & Video recording of resuscitation & $1(0.8)$ \\
\hline & Other $^{\ddagger}$ & $7(5.5)$ \\
\hline \multirow{6}{*}{$\begin{array}{l}\text { Do respondents obtain written consent to record } \\
\text { patients' data on their personal mobile device? }\end{array}$} & Never & $75(58.6)$ \\
\hline & Rarely & $24(18.8)$ \\
\hline & Sometimes & $12(9.4)$ \\
\hline & Often & $4(3.1)$ \\
\hline & Always & $2(1.6)$ \\
\hline & Unknown ${ }^{\S}$ & $11(8.6)$ \\
\hline \multirow{6}{*}{$\begin{array}{l}\text { Do respondents obtain verbal consent to record } \\
\text { patients' data on their personal mobile device? }\end{array}$} & Never & $14(10.9)$ \\
\hline & Rarely & $5(3.9)$ \\
\hline & Sometimes & $23(18.0)$ \\
\hline & Often & $21(16.4)$ \\
\hline & Always & $4(3.1)$ \\
\hline & Unknown ${ }^{\S}$ & $9(7.0)$ \\
\hline \multirow{6}{*}{$\begin{array}{l}\text { Do respondents document the verbal consent on } \\
\text { the patients' medical record? }\end{array}$} & Never & $55(43.0)$ \\
\hline & Rarely & $23(18.0)$ \\
\hline & Sometimes & $20(15.6)$ \\
\hline & Often & $7(5.5)$ \\
\hline & Always & $14(10.9)$ \\
\hline & Unknown ${ }^{\S}$ & $9(7.0)$ \\
\hline \multirow{6}{*}{$\begin{array}{l}\text { Storage of patient data on respondents' personal } \\
\text { mobile device. }\end{array}$} & Remains solely on personal mobile device & $56(43.8)$ \\
\hline & Transferred via emails or text messaging & $51(39.8)$ \\
\hline & Manually backed up in online storage & 40 (31.3) \\
\hline & Automatically backed up in online storage & $39(30.5)$ \\
\hline & Transferred to other devices using a cord & $11(8.6)$ \\
\hline & Do not know & $2(1.6)$ \\
\hline \multicolumn{3}{|c|}{$\begin{array}{l}\mathrm{CT}=\text { computed tomography; ECG = electrocardiogram; MRI = magnetic resonance imaging; US = ultrasound. } \\
\text { *\% = N/128 (Total number of participants who responded to these questions). } \\
\text { "Ultrasound log; research; follow-up; for delayed input in electronic medical record (EMR); and communication with RNs. } \\
\text { FCensus of ED. } \\
\text { "C Question unanswered. }\end{array}$} \\
\hline
\end{tabular}

urban academic hospitals $(56.5 \%$ and $78.7 \%$, respectively) (Supplementary Material).

Participant use of personal mobile devices to record patient data in the ED is presented in Table 1. Overall,
$31.5 \%$ (95\% confidence interval [CI] $27.0 \%-36.3 \%$ ) of EPs and residents surveyed reported using personal mobile devices to record patient data, at least monthly by $78.1 \%$ and every shift by $7.0 \%$. The reported use of 
personal mobile devices to record patient data was most common for communication with consultants (78.1\%) and medical education (65.6\%). Most reported their personal mobile device is password protected, and they used the native application of their personal mobile device to record patient data $(89.8 \%$ and $76.6 \%$, respectively).

Of participants who reported using personal mobile devices to record patient data, $77.8 \%$ (95\% CI 69.1\%$84.3 \%$ ) indicated that they obtained written consent rarely or never. Participants reported obtaining verbal consent sometimes $(18.0 \%)$, often $(16.4 \%)$, or always $(43.8 \%)$ and documenting this consent rarely $(18.0 \%)$ or never (43.0\%). Fourteen participants (10.9\%) reported not obtaining any consent.

Approximately one-third of participants (36.7\%) indicated that using personal mobile devices to record patient data improves the care provided by consultants and expedites management (31.3\%). In qualitative responses, many suggested personal mobile device use to record patient data improves patient flow by promoting efficient communication with consultants.

Approximately one-third of participants (32.8\%) indicated that using personal mobile devices to record patient data aids medical education. Recurrent descriptive themes of responses included using personal mobile device recorded data for general teaching, formal didactic sessions, or presentation of cases.

A minority of participants believed that using personal mobile devices to record patient data did not (9.4\%) affect care or have a negative effect $(5.2 \%)$ on care. Qualitatively, participants described these negative effects as time-consuming, distracting, or threatening privacy and confidentiality.

Over one-half of the participants (53.2\%) were unaware of regulations at their institution, and of those who were, $19.7 \%$ felt restricted by them. Most participants suggested that changes to regulations or physician practice patterns may allow improved use of personal mobile devices to record patient data.

\section{DISCUSSION}

To our knowledge, this is the first study investigating EP and resident use of personal mobile devices for recording patient data in Canadian EDs. It is already known that personal mobile device use is ubiquitous in the medical community. ${ }^{1,10}$
Most participants indicated that recording patient data with personal mobile devices is beneficial for a number of reasons. Few participants indicated personal mobile device use to record patient data is detrimental, and most concerns were related to privacy and confidentiality. Patient data recorded on personal mobile devices included information that can be difficult to describe or needs specific expertise to interpret. Recording patient data for medical education purposes is frequent and included rare conditions or presentations to which learners may not otherwise be exposed. When recording patient data with a personal mobile device, participants indicated they were unlikely to obtain written consent, whereas seeking verbal consent was more common, but rarely documented. Our findings suggest that the majority of Canadian EPs and residents do take some steps to secure the information on their devices. Consistent with research in other disciplines, over one-half of the participants were unaware of regulations regarding personal mobile device use to record patient data. ${ }^{7}$

Canadian EPs and residents should be aware of several privacy issues surrounding personal mobile device use to record patient data in the ED. The Canadian Medical Protective Association (CMPA) advises that consent for recording patient data should always be obtained and documented, and extra care applies with non-encrypted formats. ${ }^{6}$ The Federal Personal Information Protection and Electronic Documents Act and individual provincial legislation state that recorded patient information should be securely stored and shared within Canada that is not the case with many personal mobile devices. ${ }^{11}$ This is a dynamic field in which technology may provide some solutions. For example, ShareSmart ${ }^{\mathrm{TM}}$ and Hypercare ${ }^{\odot}$ are recently released Canadian personal mobile device applications that are compliant with privacy legislation. ${ }^{12,13}$ These applications have encrypted texting platforms and the ability to include consent with documentation.

\section{LIMITATIONS}

The major limitation of our study was the low response rate and resulting potential for nonresponse bias. When our demographics were compared with those from a recent comprehensive national study, work environment appeared representative; however, residents and EM-certified physicians appeared over-represented in our sample. ${ }^{14}$ The resident responses might not 
completely reflect those in EM as the CAEP database includes non-EM residents. Our low response rate, as well as the over-representation of certain groups, may reduce the generalizability of our results. In addition, the potential for sampling bias exists because of the limitations of contacting physicians. Our study was also limited to a Canadian population, where laws, guidelines, and regulations differ from those of other countries. To ensure anonymity, limited demographic information was obtained that precluded our ability to carry out detailed, categorized analyses. Despite being an anonymous survey, the potential for social desirability bias in responses exists.

\section{CONCLUSIONS}

Personal mobile device use by EPs and residents for recording patient data is common in Canadian EDs, both for communication with consultants and medical education purposes. Most Canadian EPs and residents believe personal mobile devices use to record patient data positively influences patient care. Further studies are required to determine if patient care improves with the use of personal mobile devices to record patient data and whether this involves privacy breaches.

Acknowledgements: This research received no specific grant from any funding agency, commercial, or not-for-profit sectors.

Supplementary material: The supplementary material for this article can be found at https://doi.org/10.1017/cem.2019.29

Competing interests: None.

\section{REFERENCES}

1. Koehler N, Vujovic O, McMenamin C. Healthcare professionals' use of mobile phones and the internet in clinical practice. Fournal MTM 2013;2(1):3-13.

2. O'Reilly MK, Nason GJ, Liddy S, et al. DOCSS: doctors on-call smartphone study. Ir 7 Med Sci 2014;183(4):573-7.
3. Lund A, Joo D, Lewis K, Arikan Y, Grunfeld A. Photodocumentation as an emergency department documentation tool in soft tissue infection: a randomized trial. CFEM 2013;15 (6):345-52.

4. Bullard TB, Rosenberg MS, Ladde J, et al. Digital images taken with a mobile phone can assist in the triage of neurosurgical patients to a level 1 trauma centre. 7 Telemed Telecare 2013;19(2):80-3.

5. Sikka N, Carlin KN, Pines J, et al. The use of mobile phones for acute wound care: attitudes and opinions of emergency department patients. 7 Health Commun 2012;17(1 Suppl 1):37-42.

6. The Canadian Medical Protective Association. Duties and Responsibilities. CPMA; 2018. Available at: https://www. cmpa-acpm.ca/en/advice-publications/browse-articles/dutiesand-responsibilities (accessed October 25, 2015).

7. Kornhaber R, Betihavas V, Baber RJ. Ethical implications of digital images for teaching and learning purposes: an integrative review. 7 Multidiscip Healthc 2015;8:299-305.

8. Bhangoo P, Maconochie IK, Batrick N, Henry E. Clinicians taking pictures-a survey of current practice in emergency departments and proposed recommendations of best practice. Emerg Med 7 2005;22(11):761-5.

9. Burns KE, Duffett M, Kho ME, et al. A guide for the design and conduct of self-administered surveys of clinicians. CMAZ 2008;179(3):245-52.

10. Dexheimer JW, Borycki EM. Use of mobile devices in the emergency department: A scoping review. Health Informatics F 2015;21(4):306-15.

11. Office of the Privacy Commissioner of Canada. PIPEDA legislation and regulations. Gatineau; OPC; 2015. Available at: https://www.priv.gc.ca/en/privacy-topics/privacy-laws-incanada/the-personal-information-protection-and-electronicdocuments-act-pipeda/r_o_p/ (accessed December 2, 2017).

12. ShareSmart ${ }^{\mathrm{TM}}$. Security at its core. Think Tank Innovations Ltd; 2017. Available at: https://sharesmart.ca/en/security/ (accessed December 2, 2017).

13. Hypercare@. Privacy policy. Hypercare; 2018. Available at: https://www.hypercare.com/privacy-policy (accessed June 7, 2018).

14. Collaborative Working Group on the Future of Emergency Medicine in Canada. Emergency Medicine training and practice in Canada: Celebrating the past and evolving for the future. Ottawa, ON: The Canadian Association of Emergency Physicians, the College of Family Physicians Canada, and the Royal College of Physicians and Surgeons of Canada; 2016. Available at: https://caep.ca/wp-content/uploads/ 2017/07/cwg0001_cwg-em_report_-_august_-_final_web.pdf (accessed Dec 28, 2018). 